\title{
Autologous Bone Marrow-Derived Stem Cell Transplantation In Patients With Child C Liver Cirrhosis Comparative Study
}

\author{
Research Article
}

El Garem NH${ }^{1}$, Amin $\mathrm{MA}^{1 *}$, Metwalli $\mathrm{HG}^{2}$, El Shenawy $\mathrm{IG}^{1}$, Hussien $\mathrm{MA}^{1}$

${ }^{1}$ Departments of Internal Medicine, Faculty of Medicine, Cairo University, Egypt.

${ }^{2}$ Departments of Clinical Pathology, Faculty of Medicine, Cairo University, Egypt.

\section{Abstract}

Background: Adult stem cell therapy could help patients with child C liver cirrhosis .

Aim and methods: to evaluate the effect of autologous transplantation of BM-derived mononuclear cells subjected to ex vivo hepatocyte differentiation and BM-derived undifferentiated mesenchymal stem cells in cirrhotic patients, and assessing the safety and efficacy of transplantation of these cells via direct intrasplenic injection. 30 patients with Child $\mathrm{C}$ cirrhosis were enrolled, They were divided into three groups. Group 1: 10 patients who received bone marrow derived mononuclear cells after ex vivo hepatocyte differentiation. Group 2: 10 patients; who received bone marrow derived undifferentiated mesenchymal stem cells. Group 3: 10 patients who were maintained on their ordinary liver supportive treatment . Bone marrow aspiration was done from the posterior superior iliac spine. After MNCs separation, induction of hepatocyte differentiation by co-cultures with hepatocyte growth factor and basic fibroblast growth factor were done and demonstration of alpha fetoprotein and albumin gene expression were used as markers of hepatocyte differentiation, the cells were then injected to group 1 patients in a dose of $5 \times 106 / \mathrm{ml}$ suspended in $5 \mathrm{ml}$ sterile saline via intrasplenic route under ultrasonic guidance. Isolation of mesenchymal stem cells was done followed by primary culture and subculture of the isolated cells. Flow cytometry was used to identify MSCs by surface expression of CD44, CD73, and CD34. Group 2 were injected with undifferentiated mesenchymal stem cells in a dose of $5 \times 106 / \mathrm{ml}$ suspended in $5 \mathrm{ml}$ sterile saline via intrasplenic route . Control group remained on their medical liver supportive measures. Monthly liver function were done for 6 months follow up . Results: there was a statistically significant improvement in the hepatic synthetic function and possible reduction in mortality in patients received stem cell therapy compared to control group. Statistical comparisons between the two transplanted groups did not merit any significant difference.

Conclusion: Transplantation of either BM- derived mononuclear cells after ex vivo hepatocyte differentiation or BMderived undifferentiated mesenchymal cells can be used as a potential treatment for liver cirrhosis. Also intrasplenic route of cells injection is both safe and feasible.

Keywords: Liver Cirrhosis; Stem Cell; Mononuclear Cells; Mesenchymal Cells.

\section{Introduction}

Cirrhosis is defined as the histological development of regenerative nodules surrounded by fibrous bands in response to chronic liver injury that leads to portal hypertension and end stage liver disease [1] . Recent advances in the understanding of the natural history and pathophysiology of cirrhosis, and in treatment of its complications, resulting in improved management, quality of life and life expectancy of cirrhotic patients. At present, liver trans- plantation remains the only curative option for a selected group of patients, but pharmacological therapies that can halt progression to decompensated cirrhosis or even reverse cirrhosis are currently being developed [2]. At present orthotopic liver transplantation is the only therapeutic option for patients with acute and chronic ESLDs. Liver transplantation, however, has the disadvantage of requiring lifelong immunosuppression and follow up, with $10-15 \%$ of patients dying whilst on the waiting list due to the shortage of donated organs. In 2005, only one-third of patients

*Corresponding Author

Mona A Amin,

Departments of Internal Medicine, Faculty of Medicine, Cairo University, Egypt.

Email: monasleman@hotmail.com

Received: August 24, 2016

Accepted: September 16, 2016

Published: October 12, 2016

Citation: El Garem NH, Amin MA, Metwalli HG, El Shenawy IG, Hussien MA (2016) Autologous Bone Marrow-Derived Stem Cell Transplantation In Patients With Child C Liver Cirrhosis Comparative Study. Int I Stem Cell Res Transplant. 04(8), 228-234. doi: http://dx.doi.org/10.19070/2328-3548-1600035

Copyright: Amin $\mathbf{M A}^{\circ}$ 2016. This is an open-access article distributed under the terms of the Creative Commons Attribution License, which permits unrestricted use, distribution and reproduction in any medium, provided the original author and source are credited. 
waiting for a liver transplant were transplanted. With the number of donor organs likely to decrease over the coming decades, research into the alternative methods of treatment of whole-organ transplant is essential. Hepatocyte transplantation has been suggested as an alternative to liver transplantation, especially for hepatic disorders caused by inherited protein deficiency [3].

\section{Patients and Methods}

After ethical approval by the ethical committee of internal medicine department and informed written consents from patients, 30 patients with Child C liver cirrhosis were selected from the inpatients of internal medicine department- Kasr Al Ainiy hospitals Cairo University. They were divided into 3 groups. Group 1 included 10 patients who received bone marrow derived mononuclear cells subjected to ex vivo hepatocyte differentiation. Group 2 included 10 patients who received bone marrow derived undifferentiated mesenchymal stem cells. Group 3 included 10 patients maintained on their ordinary liver supportive treatment including albumin transfusion, fresh plasma and vitamin $K$, serving as a control group.

\section{Inclusion Criteria}

Thirty adult patients with Child C class liver cirrhosis having: ascites, low prothrombin time, low serum albumin less than $3 \mathrm{~g} / \mathrm{dl}$ and some have past history of hepatic encephalopathy.

\section{Exclusion Criteria}

Patients with hepatocellular carcinoma, concomitant renal failure or heart failure, Patients with severe bleeding tendency and Pregnant female patients.

\section{All Patients were Subjected to the Following}

Complete clinical evaluation, Routine laboratory investigations including Liver and kidney function tests, fasting and postprandial blood sugar, Complete blood picture, Alpha fetoprotein, Hepatitis markers for HBV and HCV, and abdominal ultrasonography. Bone marrow aspirate was performed to group 1 and 2 patients from the posterior superior iliac spine to obtain hematopoietic stem cells.

\section{Sample Collection}

Under aseptic conditions, $30-40 \mathrm{ml}$ of bone marrow were aspirated from the posterior superior iliac spine under local anesthesia in sterile heparinized vacutainer tubes to be handled within 6 hours.

\section{Mononuclear Cell (MNC) Separation and Differentiation}

MNCs were separated using ficol hypaque density gradient centrifugation. Cell pellets were suspended in $1 \mathrm{ml}$ serum free DMEM media and counted using a hemocytometer. Counting and viability was assessed by the vital stain trypan blue $(0.4 \%)$ exclusive dye (Sigma).

Induction of hepatocyte differentiation according to the method used by Abdi et al., 2009. Briefly $20 \mathrm{ng} / \mathrm{ml}$ hepatocyte growth factor and $10 \mathrm{ng} / \mathrm{ml}$ basic fibroblast growth factor were added to $5 \mathrm{ml}$ complete DMEM (20\% autologous serum, 10\% penicillin-streptomycin-fungisone) were added to 5 million cells [4].

\section{Evaluation of Hepatocyte Differentiation was Done Through}

1. Morphological examination of dishes under inverted microscope.

2. Detection of gene expression of albumin and AFP by RT-PCR where RNA extraction was done using RNeasy protect cell mini kit (Qiagen cat no 74624) according to manufacturer's instructions. RT-PCR was done using GeneAmp ${ }^{\circledR}$ Gold RNA PCR Core Kit according to manufacturer instructions (table 1).

Reaction tubes were incubated for 10 minutes at $94^{\circ} \mathrm{C}$ as a first denaturation step followed by 40 cycles of 1 minute at $94^{\circ} \mathrm{C}$ (denaturation), 1 minute at $58^{\circ} \mathrm{C}$ for AFP and albumin and $56^{\circ} \mathrm{C}$ for $\beta$-actin (annealing) and 1 minute at $72^{\circ} \mathrm{C}$ (extension) followed by a final elongation step for 7 minutes at $72^{\circ} \mathrm{C}$.

3. Measurement of albumin in the supernatant was done according to Cembrowski GS, 1990, where supernatant of each culture were collected at the indicated time points and stored at-20oC in aliquots [5]. Albumin was then measured in the samples using immunoturbidometric method used for assessment of microalbumin using the SYNCHRON system

The total mononuclear cell count ranged from $7.5 \times 10^{7}$ cells/ sample and viability was $97-100 \%$. Cells were washed using phosphate buffered saline and suspended in $5 \mathrm{ml}$ sterile saline in a dose of 5 million cells $/ \mathrm{ml}$ (Figure 1).

\section{Mesenchymal Stem Cell Separation and Identification}

Isolation, primary culture and subculture of MSCs was done according to the method used by Allan EH et al., 2005. Flasks used were incubated in a horizontal position in humidified incubator at $37 \mathrm{oC}$ and $5 \% \mathrm{CO}_{2}$. The first change of media was at day 2 to remove non adherent cells, then the media were changed twice weekly until reaching $70 \%-90 \%$ confluency which was assessed by the inverted microscope. The adherent cells were harvested by trypsinization using $0.25 \%$ trysin-EDTA solution. After trypsnization, cells were examined under the microscope, counted and the viability was assessed using the trypan blue dye [6]. Flow cytometry was done to evaluate surface expression. Results were declared as percentage of cells expressing CD44, CD73 and CD34 in the gated population of mononuclear cells. Subculture of MSCs was done according to the method used by Kang et al., 2006 [7].

The count of isolated MSC cells ranged from 1.5 to $3.2 \times 10^{6}$ / sample, their viability was $92-96 \%$. Under the inverted microscope, the cells have shown heterogeneity between floating and adherent cells (Figure 2).

Cells were washed using phosphate buffered saline and suspended in $5 \mathrm{ml}$ sterile saline in a dose of 5 million cells $/ \mathrm{ml}$.

The cells were injected under sonographic guidance and complete aseptic precaution into the spleen of the patients using a needle gauge $20 \mathrm{~F}$. 
Table 1. Shows the Primers used for Detection of AFP and Albumin.

\begin{tabular}{|c|c|c|c|}
\hline Target gene & Sequence & Size & $\begin{array}{c}\text { Annealing } \\
\text { Temperature }\end{array}$ \\
\hline AFP & F : GATGCACCTGACCCACTTTATAAA & \multirow{2}{*}{$322 \mathrm{bp}$} & $58^{\circ} \mathrm{C}$ \\
\cline { 2 - 2 } & R: GAGATTGTCTGACCGATTCAGACT & & \\
\hline Albumin & F: CAACTATGTCCGTGAGCTTCCA & \multirow{2}{*}{$339 \mathrm{bp}$} & $58^{\circ} \mathrm{C}$ \\
\cline { 2 - 2 } & R:GTGTCGGTGCTGGTCTATATG & & \\
\hline
\end{tabular}

Figure 1. A) Mononuclear Cells Under Inverted Microscope (40X), B) Hepatocytes Induced among the Cellular Culture Under Inverted Microscope (40X).
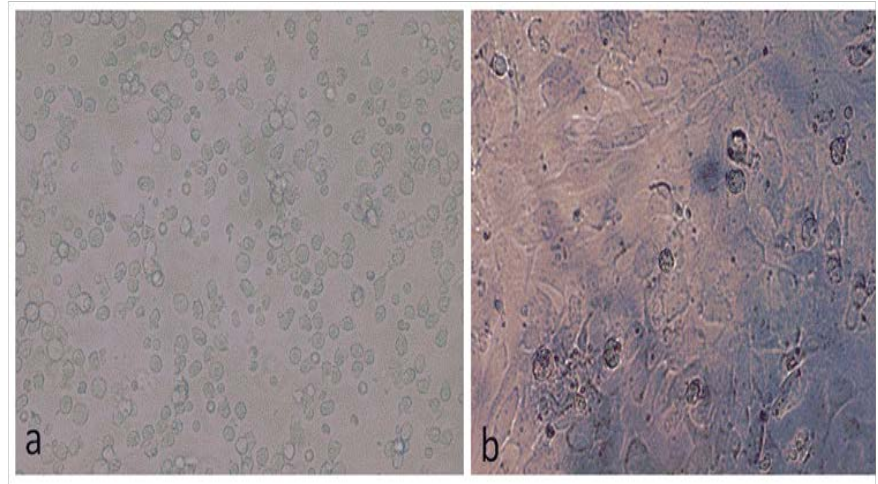

Figures 2. Show the Different Morphological Changes in the MSCS using the Inverted Microscope: A) Inverted Microscope Image X400 24hr of Primary Culture Show Heterogeneity Between Floating and Rounded Adherent Cells, B) Inverted Microscope Image X200 Spindle Shaped Cells Appeared Between The Rounded Cells On Day 2, C) Inverted Microscope Image X200 Show Colonies of Fibroblastoid Cells Appeared on 3rd Day, D) Inverted Microscope Image X200 Fibrblastiod Cells Day 12 with 80-90\% Confluence, E) Inverted Microscope Image X400 Of Subcultured Mscs Showing Much More Pure Cells.
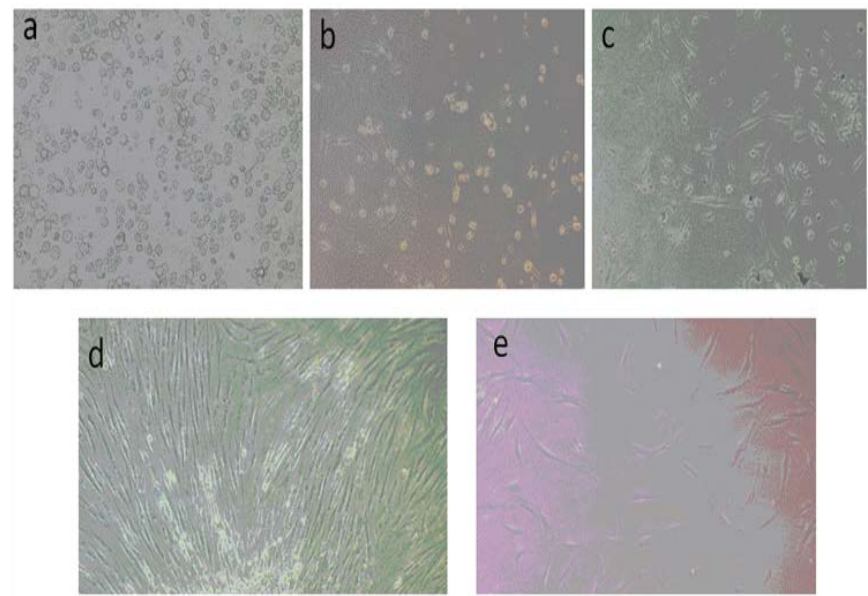

The three groups of patients were regularly followed up by clinical evaluation and laboratory investigation mainly liver function tests which were done monthly for 6 months follow up period.

\section{Statistical Methods}

Data were analyzed using SPSS statistical package version 17 . For numerical data, parametric data were expressed as mean, standard deviation and range, while non-parametric data were expressed as median and interquartile range. Qualitative data were expressed as frequency and percentage. Chisquare test or Fisher's exact test were used to examine the relation between qualitative variables. Nonparametric numerical data were analyzed using Mann-Whit- ney test. P-value less than 0.05 was considered significant.

\section{Results}

There were no statistical significant differences between the three groups as regards the age, sex and the presence of diabetes or hypertension. Group 1 (6 males and 4 females) their age ranged from 35-65 years with a mean value of $52.10 \pm 9.99$ years, group 2 (6 males and 4 females) their age ranged from 47-61 years with a mean value of $53.40 \pm 4.67$ years, and group 3 : $(6$ males and 4 females) their age ranged from 50-63 years with a mean value of $57.0 \pm 4.03$ years. 
There were no statistical significant differences between the three groups as regards the baseline weight, MELD score, total bilirubin, direct bilirubin, AST, ALT, Albumin, PC and INR (Table 2) .

Three months after stem cell therapy, the total bilirubin showed statistically significant difference between group 2 and the control group $(\mathrm{P}<0.04)$ but no statistically significant difference between group 1 and the control group or between group 1 and 2 whereas at the end of 6 months the total serum bilirubin had a statistically significant difference between groups 1 and 2 in relation to the control group $(\mathrm{P}<0.001)$. There was a statistically significant decrease in the total bilirubin level between the baseline and at the end of 6 month follow up in group $1(\mathrm{P}<0.001)$ and group $2(\mathrm{P}<$ $0.002)$ but not in the control group $(\mathrm{P}=0.06)$.

Serum level of AST and ALT showed no statistically significant difference between the three groups both at the end of the three months and six months and between the baseline and at the end of 6 month follow up in the three groups.

Serum albumin level after three months showed statistically significant difference between group 1 and the control group $(\mathrm{P}<$ 0.01 , while group 2 showed no difference in relation to group 1 and the control group whereas at the end of 6 months follow up serum albumin levels had a statistically significant difference between groups 1 and 2 in relation to the control group $(\mathrm{P}<0.001)$ but not in relation to each other. There was a statistically significant increase in the serum albumin level between the baseline and at the end of 6 month follow up both transplanted groups $(\mathrm{P}<0.001)$, while in the control group there was a statistically significant decrease of serum albumin $(\mathrm{P}<0.01)$.
The serum albumin was maintained in patients of group 1 and 2 without intravenous administration of human albumin or plasma. While in control group serum albumin levels were decreasing throughout follow up period in spite of administration of intravenous albumin and fresh plasma.

There was a statistically significant increase in the prothrombin concentration between the baseline and at the end of 6 month follow up in group $1(\mathrm{P}<0.002)$ but a non-significant increase in group 2, while in the control group there was a significant decrease of $\mathrm{PC}(\mathrm{P}<0.04)$.

There was a statistically significant decrease in the INR between the baseline and at the end of 6 month follow up in group $1(\mathrm{P}<$ $0.03)$ and group $2(\mathrm{P}<0.046)$, while in the control group there was a non- significant increase of INR. (Tables $3 \& 4$, Figure 3 )

At 3 months the body weight, there was a statistically significant difference between group 1 and the control $(\mathrm{P}<0.04)$ but no statistically significant difference between group 1 and group 2 or between group 2 and the control. At the end of 6 month follow up the weight, there was a statistically significant difference between group 1 and the control $(\mathrm{P}<0.046)$ but no statistically significant difference between group 1 and group 2 or between group 2 and the control.

There was a statistically significant decrease in body weight between the baseline and at the end of 6 month follow up in group $1(\mathrm{P}=<0.001)$ and group $2(\mathrm{P}=<0.001)$, while in the control group there was a significant increase of body weight $(\mathrm{P}=0.004)$.

At 3 months the MELD score, there was no statistically signifi-

Table 2. Shows the Baseline Laboratory Data of the Three Groups.

\begin{tabular}{|c|c|c|c|c|}
\hline & Group 1 & Group 2 & control & P \\
\hline Total bilirubin $\mathrm{mg} / \mathrm{l}$ & $3.15 \pm 1.28$ & $2.49 \pm 0.77$ & $3.34 \pm 1.43$ & 0.3 \\
\hline Direct bilirubin $\mathrm{mg} / 1$ & $1.70 \pm 0.82$ & $1.17 \pm 0.51$ & $1.76 \pm 0.73$ & 0.1 \\
\hline AST U/1 & $66.60 \pm 33.13$ & $70.60 \pm 15.53$ & $63.5 \pm 24.65$ & 0.8 \\
\hline ALT U/1 & $45.80 \pm 31.88$ & $34.50 \pm 8.50$ & $35.80 \pm 25.22$ & 0.5 \\
\hline Albumin g/dl & $2.51 \pm 0.22$ & $2.25 \pm 0.46$ & $2.50 \pm 0.32$ & 0.2 \\
\hline PC \% & $50.00 \pm 9.56$ & $53.27 \pm 9.87$ & $44.20 \pm 10.98$ & 0.2 \\
\hline INR & $1.66 \pm 0.19$ & $1.62 \pm 0.24$ & $1.86 \pm 0.29$ & 0.08 \\
\hline
\end{tabular}

$* \mathrm{P}<0.05$ is considered significant.

Table 3. Demonstrates the Laboratory Data after 3 Months Follow Up of the Three Groups.

\begin{tabular}{|c|c|c|c|c|}
\hline & Group 1 & Group 2 & control & P \\
\hline Total bilirubin mg/dl & $2.40 \pm 1.02$ & $1.93 \pm 0.63$ & $3.38 \pm 1.11$ & $0.04 *$ \\
\hline Direct bilirubin mg/dl & $1.25 \pm 0.50$ & $1.00 \pm 0.48$ & $2.24 \pm 0.98$ & $0.008^{*}$ \\
\hline AST U/1 & $74.11 \pm 30.33$ & $70.88 \pm 10.32$ & $61.20 \pm 3.90$ & 0.5 \\
\hline ALT U/1 & $48.89 \pm 21.75$ & $33.50 \pm 2.62$ & $32.00 \pm 2.45$ & 0.06 \\
\hline Albumin g/dl & $2.79 \pm 0.19$ & $2.49 \pm 0.51$ & $2.12 \pm 0.29$ & $0.01 *$ \\
\hline PC $\%$ & $49.89 \pm 9.77$ & $52.63 \pm 10.94$ & $45.20 \pm 13.68$ & 0.5 \\
\hline INR & $1.66 \pm 0.22$ & $1.65 \pm 0.26$ & $1.83 \pm 0.32$ & 0.5 \\
\hline & $* \mathrm{P}<0.05$ is considered significant.
\end{tabular}


Table 4. Demonstrates the Laboratory Data after 6 Months Follow Up of the Three Groups.

\begin{tabular}{|c|c|c|c|c|}
\hline & Group 1 & Group 2 & control & P \\
\hline Total bilirubin $\mathrm{mg} / \mathrm{dl}$ & $1.71 \pm 0.76$ & $1.16 \pm 0.24$ & $3.21 \pm 0.21$ & $<0.001^{*}$ \\
\hline Direct bilirubin $\mathrm{mg} / \mathrm{dl}$ & $0.87 \pm 0.48$ & $0.57 \pm 0.19$ & $1.97 \pm 0.12$ & $<0.001^{*}$ \\
\hline AST U/1 & $63.50 \pm 31.57$ & $65.43 \pm 11.27$ & $53.33 \pm 3.06$ & 0.7 \\
\hline ALT U/1 & $42.25 \pm 24.63$ & $34.14 \pm 3.02$ & $29.00 \pm 1.73$ & 0.5 \\
\hline Albumin g/dl & $3.10 \pm 0.15$ & $2.96 \pm 0.16$ & $2.00 \pm 0.10$ & $<0.001 *$ \\
\hline PC \% & $56.25 \pm 9.47$ & $57.00 \pm 11.27$ & $45.00 \pm 13.23$ & 0.3 \\
\hline INR & $1.50 \pm 0.17$ & $1.55 \pm 0.23$ & $1.83 \pm 0.33$ & 0.1 \\
\hline
\end{tabular}

$* \mathrm{P}<0.05$ is considered significant.

Figures 3. Shows the Changes in the Liver Functions throughout the Follow Up Period in the Three Groups (Total Bilirubin, Serum Albumin, PC and INR).

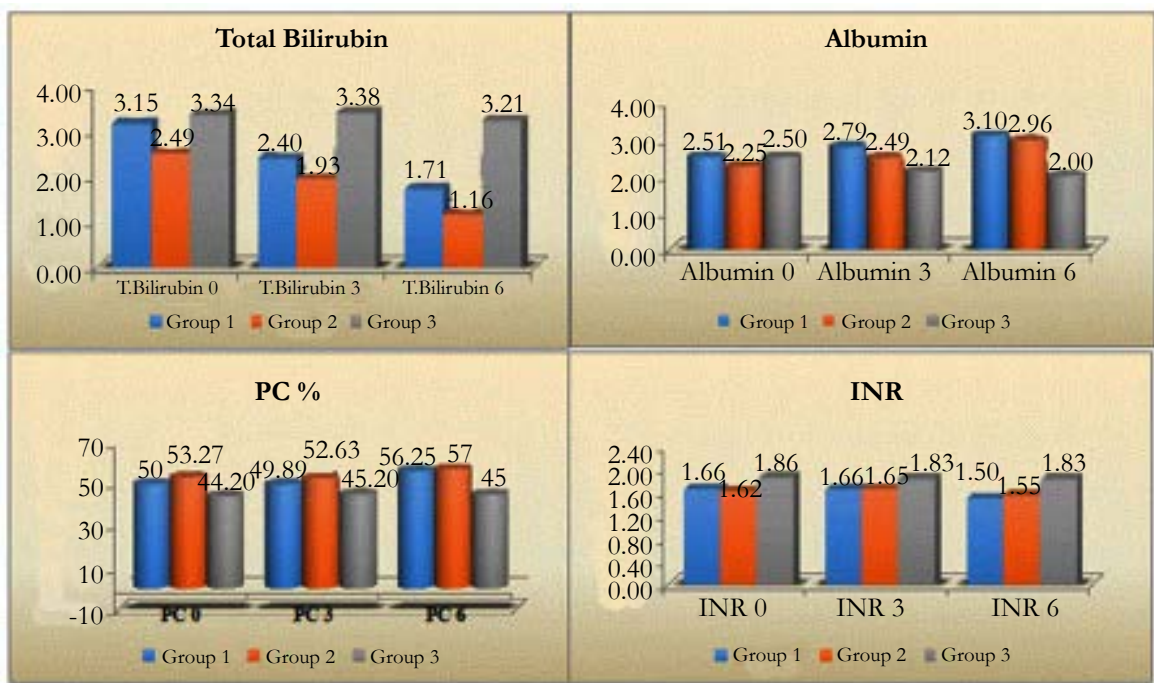

Figure 4. The Changes of the Meld Score and Body Weight in the Three Studied Groups Throughout the Follow Up Period.

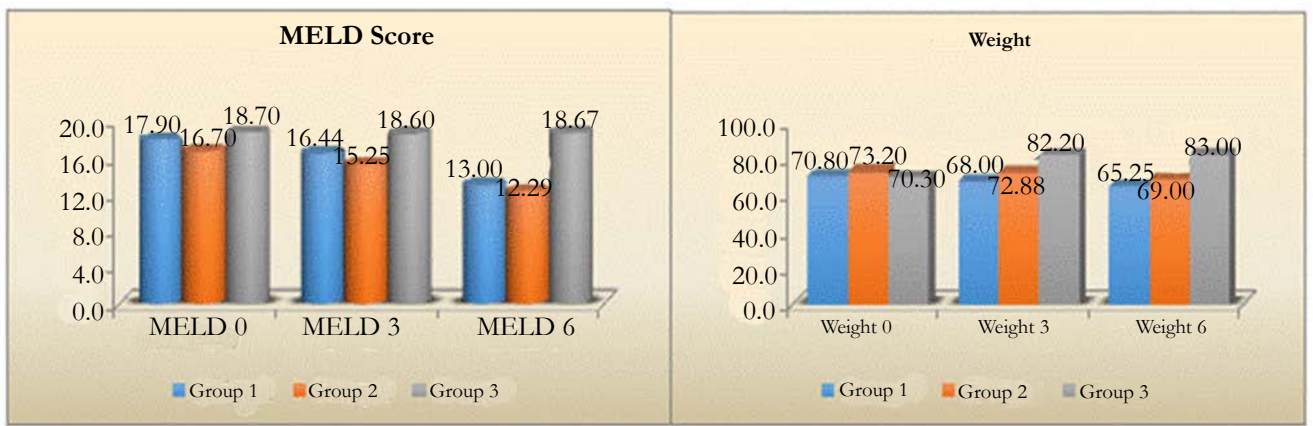

cant difference between the three groups. At the end of 6 month follow up the MELD score, there was a significant difference between groups 1 and 2 in relation to the control group $(\mathrm{P}=0.001)$ but not in relation to each other.

There was a statistically significant decrease in MELD score between the baseline and at the end of 6 month follow up in group $1(\mathrm{P}<0.001)$ and group $2(\mathrm{P}<0.001)$, while in the control group there was a non-significant increase of MELD score (Figure 4).

Mortality rate in group 1 was $20 \%(2 / 10)$, in group 2 the mortality was $30 \%(3 / 10)$, while in the control group it was $70 \%(7 / 10)$ during the follow up period.

Despite the large difference between groups 1 and 2 with the control group regarding mortality but this was of statistical nonsignificance due to small sample size $(\mathrm{P}=0.054)$.

\section{Discussion}

Stem cells have recently shown promise in cell therapy because they have the capacity for self-renewal and multilineage differentiation, and are applicable to human diseases. Transplantation of BMSCs can restore liver mass and function, alleviate fibrosis, 
and correct inherited liver diseases. Therefore, it can significantly improve the liver function of patients with terminal liver disease, with good safety and effectiveness [8].

Adult hematopoietic stem cells transdifferentiate to hepatocytes by culturing this cells in special media with addition of hepatocyte growth factor, and to ensure that the human stem cells developed into liver-like cells, the researchers tested for the presence of a human protein, albumin that is only produced by the liver [9].

Hepatocytes are well engrafted when injected into the splenic pulp as they are entrapped in the sinusoids and vascular spaces [10]. Hepatocytes can proliferate and replace approximately $40 \%$ of the splenic pulp and retain synthetic, metabolic and biliary transport functions [11].

Theise and coworkers studied autopsy and liver biopsy tissue from recipients of sex-mismatched therapeutic bone marrow and orthotopic liver transplantations. They identified hepatocytes and cholangiocytes of bone marrow origin by immunocytochemistry staining for CK8, CK18, and CK19 and FISH analysis for the Y-chromosome. They found up to $43 \%$ of hepatocytes and $38 \%$ of cholangiocytes were engrafted, showing that these cells can be derived and differentiated from bone marrow to replenish the liver [12].

MSCs have the characteristics of being easily available, highly proliferative, easily transfectable, resistant to cryopreservation damage and to display a large in vitro and in vivo differentiation potential [13].

A number of studies have suggested that MSCs may differentiate into hepatocyte-like cells in vitro or in vivo. As for HSCs, transdifferentiation of MSCs to hepatocyte-like cells in vivo may in part be due to fusion, but some reports suggest cell-autonomous transdifferentiation $[14,15]$.

The present work was performed to evaluate the effect of transplantation of bone marrow derived mononuclear cells that have been subjected to ex vivo hepatocyte differentiation versus undifferentiated mesenchymal stem cells on hepatocyte regeneration in patients with Child $\mathrm{C}$ class liver cirrhosis. It also aimed at the assessment of the safety and efficacy of the intrasplenic route for the injection of the stem cells. For this purpose, 30 patients with Child $\mathrm{C}$ liver cirrhosis were enrolled. They were divided in three groups. Group 1 included 10 patients who received differentiated bone marrow derived mononuclear cells. Group 2 included 10 patients who received bone marrow derived undifferentiated mesenchymal stem cells. Control group 10 patients who remained on their medical liver supportive measures, including human albumin, fresh plasma and vitamin $\mathrm{K}$.

Follow up of patients monthly for a period of six months was done clinically and by liver function tests. There was improvement of hepatic synthetic function in the transplanted groups as compared to control group.

The survival of patients who received both the mononuclear cells after hepatocyte differentiation and the mesenchymal stem cells was much better than the control group and we observed that these patients had less hospital admission than the control group.
In our study there were no statistically significant differences in the baseline parameters of liver functions or liver enzymes between the three studied groups, and there was a statistically significant increased serum albumin and decreased serum total bilirubin in transplanted groups compared to the control group at the end of 6 months follow up, as well as a statistically significant increase in the prothrombin concentration in group 1, but a non-significant increase in group 2, while in the control group there was a significant decrease of PC. Also there was a statistically significant decrease in the INR in both transplanted groups while in the control group there was a non- significant increase of INR.

The body weight was significantly decreased and MELD score improved at the end of 6 month follow up in the transplanted groups, compared to the control group who had a significant increase of body weight, and deterioration of the MELD score.

There was no statistically significant difference between the two transplanted groups as regards serum total bilirubin, albumin, prothrombin concentration, INR, liver enzymes, MELD score or body weight at the baseline and by the end of 6 month follow up. Previously Gordon and his colleagues (2006) conducted a phase I clinical trial of the infusion of CD34+ cells into the portal vein of three patients and the hepatic artery of two patients with chronic liver disease with no adverse effects. Although these patients received relatively low numbers of cells $\left(2 \times 10^{6}\right)$, a moderate improvement in serum bilirubin was seen in 3 of the 5 patients which lasted for more than 18 months [16].

Also Terai and coworkers have also shown improvement in liver function following peripheral infusion of autologous BM cells in patients with liver cirrhosis. Nine patients who received a peripheral vein infusion of an average of $5.2 \times 10^{9}$ autologous mononuclear cells (CD34+, CD45+, and ckit + ) demonstrated significant improvement in the Child-Pugh Scores and serum levels of albumin. Liver biopsies were taken in 3 patients revealing an increase in proliferating cell nuclear antigen staining, an indirect marker of hepatocyte turnover [17].

Lyra and associates performed a study on 10 patients with chronic end-stage liver disease, receiving mononuclear-enriched BMCs via the hepatic artery. This study showed improvement in serum bilirubin, albumin, and international normalized ratio (INR) [18]. They went on to perform the first randomized controlled study of autologous BMC transplantation in liver disease. Thirty patients were randomized to receive either a placebo or $\mathrm{BMC}$, in the form of an autologous mononuclear cell preparation infused into the hepatic artery [19]. After 3 months follow up, the treated patients had a significant improvement in albumin compared to controls $(16 \%$ versus $2 \%)$ and a significant reduction in their Child-Pugh status $(-8 \%$ versus $+4 \%)$, but there was no change in the INR between the two groups.

Also in a preliminary study conducted by El-Garem and his colleagues selected sixteen patients with Child $\mathrm{C}$ class liver cirrhosis were divided into two groups: Group 1 included 10 patients who received 150,000 cells, Group 2 included 6 patients who received 2 million cells and 10 patients on their ordinary medical treatment (control group). The serum albumin, bilirubin, prothrombin time and concentration and INR improved after BMHSC therapy compared to the control group. The survival of patients who received BMHSC was better than the control group [20]. 
Also another study conducted by Salama and his colleagues included one hundred and forty patients with end stage liver diseases were randomized into two groups. Group 1, comprising 90 patients, received granulocyte colony stimulating factor for five days followed by autologous CD34+ and CD133+ stem cell infusion in the portal vein. Group 2, comprising 50 patients, received regular liver treatment only and served as a control group. The results showed near normalization of liver enzymes and improvement in synthetic function in $54.5 \%$ of the group 1 patients; $13.6 \%$ of the patients showed stable states in the infused group. None of the patients in the control group showed improvement. No adverse effects were noted [21].

Amin and her colleagues injected $10 \times 10^{6}$ of isolated human bone marrow (HBM)- stromal cells in $10 \mathrm{~mL}$ normal saline in the spleen of 20 patients with end-stage liver cirrhosis guided by the ultrasonography, and then patients were followed up on monthly basis for six months. A statistically significant decrease was detected in the total bilirubin, AST, ALT, PT and INR and a statistically significant increase in the albumin and PC [22].

Mohamed Nejad and his colleagues conducted a study included four patients transplanted with $31.73 \times 10^{6}$ of cultured autologous mesenchymal stem cells, infused through a peripheral vein. The Phase I study demonstrated no side effects and the quality of life of all four patients improved by the end of follow-up. Furthermore, MELD scores of two patients showed marked amelioration by the end of follow-up [23].

Although all clinical trials to date have shown some improvement in liver function, it must be remembered that the natural history of cirrhosis tends to be variable. Thus, one would expect some patients to improve with time, particularly in compliant patients who can be followed up. There is evidence to suggest that transplantation of only $1-5 \%$ of the total liver mass may be sufficient to restore adequate functional activity [24]. Cells can be delivered to patients via a peripheral vein, the portal vein, hepatic artery, or an intra-splenic injection.

\section{Conclusion}

Autologous BM-derived stem cells are safe and feasible in the treatment of liver cirrhosis with beneficial effects on the synthetic function of the liver and possibly reduction in mortality. Since the transplanted cells are autologous there is no need for immunosuppressive therapy, abundant supply is available and a much cheaper alternative to whole liver transplantation. Both hepatocyte differentiated bone marrow derived mononuclear cells and undifferentiated mesenchymal stem cells had the same effect on the synthetic function of the liver. Intrasplenic injection of stem cells was proved to be a safe and feasible route. Further trials are needed in the future with a bigger number of patients and with proper randomization to assess the optimum dose and route of transplantation and to evaluate the long term safety and efficacy of the procedure.

\section{References}

[1]. Ancha Baranova, Priyanka Lal, Aybike Birerdinc, Zobair M Younossi (2011) Non-Invasive markers for hepatic fibrosis. BMC Gastroenterology. 11: 91.

[2]. Schuppan D, Afdhal NH (2008) Liver cirrhosis. Lancet. 371(9615): 838-
851.

[3]. Fox IJ, Chowdhury JR, Kaufman SS, Goertzen TC, Chowdhury NR, et al., (1998) Treatment of the Crigler-Najjar syndrome type I with hepatocyte transplantation. N Engl J Med. 338(20): 1422-1426.

[4]. Abdi M, Sheykh N, Amiri I (2009) induction of differentiation of BMMSCs of rat into hepatocyte and study their biochemical factors SJKU 1388. 14(1): 9- 22.

[5]. Cembrowski GS (1990) Testing for Microalbuminuria: Promises and Pitfalls, Lab Medicine. 21(8): 491-6.

[6]. Allan EH1, Ho PW, Umezawa A, Hata J, Makishima F, et al., (2005) Differentiation potential of a mouse bone marrow stromal cell line. J Cell Biochem. 90(1):158-69.

[7]. Kang XQ1, Zang WJ, Bao LJ, Li DL, Xu XL, et al., (2006) Differentiating characterization of human umbilical cord blood-derived mesenchymal stem cells in vitro. Cell biology international. 30(7): 569-575.

[8]. Pai M1, Zacharoulis D, Milicevic MN, Helmy S, Jiao LR, et al., (2008) Autologous infusion of expanded mobilized adult bone marrow-derived CD34+ cells into patients with alcoholic liver cirrhosis. Am J Gastroenterol. 103(8):1952-1958.

[9]. Herrera MB1, Bruno S, Buttiglieri S, Tetta C, Gatti S, et al.,(2006) Isolation and characterization of a stem cell population from adult human liver. Stem Cells. 24(12): 2840-2850.

[10]. am Escht JS 2nd, Knoefel WT, Klein M, Ghodsizad A, Fuerst G, et al., (2005) Portal application of autologous CD133+ve bone marrow cells to the liver: anovel concept to support hepatic regeneration. Stem cells. 23(4):463-470.

[11]. Terai S, Segawa M, Omori K, Sakaida I (2007) Long time follow up for the patient of autologous bone marrow cell infusion (ABMI) therapy for liver cirrhosis. Hepatology. 46: 246A.

[12]. Theise ND1, Nimmakayalu M, Gardner R, Illei PB, Morgan G, et al., (2000) Liver from bone marrow in humans. Hepatology. 32(1): 11-16.

[13]. Bianco P, Robey PG (2001) Stem cells in tissue engineering. Nature. 414(6859): 118-21.

[14]. Lee MH, Yang HI, Lu SN, Jen CL, Yeh SH, et al., (2010) Hepatitis C virus seromarkers and subsequent risk of hepatocellular carcinoma: long-term predictors from a community-based cohort study. J Clin Oncol. 28(30): 4587-4593.

[15]. Banas A, Teratani T, Yamamoto Y, Tokuhara M, Takeshita F, et al., (2007) Adipose tissue-derived mesenchymal stem cells as a source of human hepatocytes. Hepatology. 46(1): 219-228.

[16]. Gordon MY1, Levicar N, Pai M, Bachellier P, Dimarakis I, et al., (2006) Characterization and clinical application of human CD34+ stem/progenitor cell populations mobilized into the blood by granulocyte colony-stimulating factor. Stem Cells. 24(7): 1822-1830.

[17]. Terai S1, Ishikawa T, Omori K, Aoyama K, Marumoto Y, et al., (2006) Improved liver function in patients with liver cirrhosis after autologous bone marrow cell infusion therapy. Stem Cells. 24(10): 2292-2298.

[18]. Lyra AC, Soares MB, Da Silva LF, Fortes MF, Pinheiro Silva AG, et al., (2007) Feasibility and safety of autologous bone marrow mononuclear cell transplantation in patients with advanced chronic liver disease. World J Gastroenterol. 13(7): 1067-1073.

[19]. Lyra AC, Soares MB, da Silva LF, Braga EL, Oliveira SA, et al., (2010) Infusion of autologous bone marrow mononuclear cells through hepatic artery results in a short-term improvement of liver function in patients with chronic liver disease: a pilot randomized controlled study. Eur J Gastroenterol Hepatol. 22(1): 33-42.

[20]. El-Garem N, Soliman M, Gabr H, Ramadan N (2008) Bone marrow derived cell transplantation in patients with decompensated cirrhosis: A preliminary study. Arab J. Gastroentrol. 9(2): 44-48

[21]. Salama H, Zekri AR, Bahnassy AA, Medhat E, Halim HA, et al., (2010) Autologous CD34+ and CD133+ stem cells transplantation in patients with end stage liver disease. World J Gastroenterol. 16(42): 5297-5305.

[22]. Amin MA, Sabry D, Rashed LA, Aref WM, el-Ghobary MA, et al., (2013) Short-term evaluation of autologous transplantation of bone marrow-derived mesenchymal stem cells in patients with cirrhosis: Egyptian study. Clin Transplant. 27(4): 607-612. DOI: 10.1111/ctr.12179.

[23]. Mohamadnejad M, Alimoghaddam K, Mohyeddin-Bonab M, et al., (2007) Phase 1 trial of autologous bone marrow mesenchymal stem cell transplantation in patients with decompensated liver cirrhosis. Arch Iranian Med. 10(4): $459-466$

[24]. Muraca M, Gerunda G, Neri D, Vilei MT, Granato A, et al., (2002) Hepatocyte transplantation as a treatment for glycogen storage disease type 1a. Lancet. 359(93): 317-318. 